\title{
Decreased Presence of Mast Cells in the Bursa Premacularis of Proliferative Diabetic Retinopathy
}

\author{
Tsunehiko Ikeda $^{\mathrm{a}}$ Kimitoshi Nakamura $^{\mathrm{b}}$ Seita Morishita ${ }^{\mathrm{a}}$ Takaki Sato $^{\mathrm{a}}$ \\ Taeko Horie $^{a}$ Teruyo Kida ${ }^{a}$ Hidehiro Oku ${ }^{a}$ Shinji Takai ${ }^{c}$ Denan Jin ${ }^{c}$ \\ aDepartment of Ophthalmology, Osaka Medical and Pharmaceutical University, Takatsuki, Japan; ${ }^{b}$ Department of \\ Ophthalmology, Nakamura Eye Clinic, Matsumoto, Japan; 'Department of Innovative Medicine, Graduate School of \\ Medicine, Osaka Medical and Pharmaceutical University, Takatsuki, Japan
}

\section{Keywords}

Mast cells - Chymase - Tryptase - Epiretinal membrane · Macular hole $\cdot$ Proliferative diabetic retinopathy $\cdot$ Bursa premacularis - Apoptosis · Semaphorin 3A

\begin{abstract}
Introduction: We previously reported that the intravitreal activities of chymase and tryptase were more increased in the patients with macular hole $(\mathrm{MH})$ and epiretinal membrane (ERM) than in those with proliferative diabetic retinopathy (PDR) and that the source of these serine proteases might be mast cells in the bursa premacularis (BPM). The purpose of this study was to compare the density of mast cells in BPM samples obtained from MH, ERM, and PDR patients. Methods: BPM and vitreous core samples were first collected during vitrectomy from eyes afflicted with vitreoretinal diseases (MH: 6 eyes, ERM: 3 eyes, and PDR: 9 eyes), and then were stained with hematoxylin, toluidine blue, antibodies against chymase and tryptase, and a terminal deoxynucleotidyl transferase dUTP nick end labeling assay kit. Results: Hematoxylin nuclear staining showed fewer positive-staining cells in the BPM samples obtained from PDR patients than in those obtained from $\mathrm{MH}$ and ERM patients. Toluidine blue staining of the BPM revealed metachromasia in the
\end{abstract}

karger@karger.com www.karger.com/ore

Karger!"
C 2021 The Author(s).

Published by S. Karger AG, Basel

This is an Open Access article licensed under the Creative Commons Attribution-NonCommercial-4.0 International License (CC BY-NC) (http://www.karger.com/Services/OpenAccessLicense), applicable to the online version of the article only. Usage and distribution for commercial purposes requires written permission. mast cells of the patients with MH and ERM, but not those of the patients with PDR. In addition, immunostaining using anti-chymase and anti-tryptase antibodies showed that the BPM samples were more intensely stained than the vitreous core samples from the patients with $\mathrm{MH}$ and ERM and that both tissue samples were poorly stained in the patients with PDR. The apoptotic cells were more frequently observed in the BPM samples from patients with MH than in those from patients with PDR. Conclusions: These findings indicated that lower activities of chymase and tryptase in the vitreous of PDR patients appeared to be attributable to the decreased presence of mast cells in the BPM. The lack of mast cells in the BPM might be related to the pathogenesis of PDR.

(c) 2021 The Author(s).

Published by S. Karger AG, Basel

\section{Introduction}

Mast cells produce chymase, tryptase, and other bioactive substances, such as histamine and tumor necrosis factor-alpha, which have been attracting attention in recent years due to the involvement in fibrosis, apoptosis, and remodeling of various tissues [1-3]. We previously reported that the intravitreal activities of chymase and tryptase, mast 
cell serine proteases, were increased in patients with macular hole (MH) and epiretinal membrane (ERM). Based on the results of our histological study, we speculated that mast cells residing in the bursa premacularis (BPM), a peculiar sac-like structure present in the premacular vitreous, might be the source of these serine proteases [4-7].

The findings in our previous study revealed that the activities of chymase and tryptase were decreased in the vitreous of proliferative diabetic retinopathy (PDR). Thus, the aim of this study was to investigate the density of mast cells in the BPM in patients with PDR, which may produce this serine protease. For this purpose, we obtained the BPM and vitreous core samples from PDR, MH, and ERM patients during vitrectomy, and stained the samples with hematoxylin, toluidine blue (metachromatic stain), and antibodies against chymase and tryptase.

\section{Methods}

\section{Collection of the BPM and Vitreous Core Samples}

All the experimental procedures performed in this study were conducted in accordance with the Association for Research in Vision and Ophthalmology $\left(\mathrm{ARVO}^{\circledR}\right)$ Statement and were approved by the Ethics Committee of Osaka Medical and Pharmaceutical University, Takatsuki-City, Osaka, Japan (approval No. 30099). The BPM and vitreous core samples were selectively collected during vitrectomy from 6 eyes of 6 patients with $\mathrm{MH}(1$ man and 5 women; mean age: 68.1 years, range: $62-77$ years), 3 eyes of 3 patients with ERM ( 2 men and 1 woman; mean age: 67.2 years, range: 60-77 years), and 9 eyes of 9 patients with PDR (5 men and 4 women; mean age: 58.6 years, range: $29-76$ years) in whom the BPM was clearly identified. None of the MH and ERM patients were associated with diabetes mellitus. In accordance with our previously reported method using a 25 -gauge vitreous surgical system $[6,7]$, the vitreous core was collected with a vitreous cutter prior to the initiation of perfusion. For the collection of the BPM samples, triamcinolone acetonide (TA) was first applied to the posterior pole of the vitreous to visualize the BPM surface after the vitreous core was widely resected (Fig. 1a). Next, a window was formed in the anterior wall of the BPM using a Diamond Dust Scraper (Synergetics USA Inc., O'Fallon, MO, USA) (Fig. 1b), and the BPM was detached from the retinal surface by suction of the posterior wall of the BPM using the vitreous cutter through the window. Simultaneously, the adhesion to the optic disc was removed (Fig. 1c). The solution in the tube connected to the vitreous cutter was then completely removed by a reverse thrust of air from the connector. Finally, the vitreous cutter was reinserted into the vitreous cavity, and the floating BPM was selectively collected (Fig. 1d).

\section{Nuclear Staining with Hematoxylin and Mast Cell Staining} with Toluidine Blue

Hematoxylin nuclear staining and toluidine blue mast cell staining were performed in 1 eye of a patient with $\mathrm{MH}$ and 1 eye of a patient with PDR. Briefly, the BPM and vitreous core samples were fixed in $4 \%$ paraformaldehyde after surgical collection and then rinsed with phosphate-buffered saline (PBS, $\mathrm{pH} 7.4$ ). The tissue samples obtained from 2 eyes ( 1 eye of a patient with $\mathrm{MH}$ and 1 eye of a patient with PDR) underwent nuclear staining with hematoxylin (Vector Laboratories Inc., Burlingame, CA, USA). Then, tissue samples obtained from the fellow eyes of those 2 patients underwent mast cell staining with $0.05 \%$ toluidine blue ( $\mathrm{pH} 4.1$; Muto Pure Chemicals Co. Ltd., Tokyo, Japan). These 4 samples were then rinsed several times in PBS, dehydrated through a graded series of ethanol and xylene, mounted with Fisher Chemical ${ }^{\mathrm{TM}}$ Permount ${ }^{\mathrm{TM}}$ Mounting Medium (Fisher Scientific, Waltham, MA, USA), and observed under a fluorescence microscope (BZ-X700; Keyence Corporation, Osaka, Japan).

\section{Immunostaining with Anti-Chymase and Anti-Tryptase}

Antibodies

Immunostaining with anti-chymase antibodies was performed in samples obtained from 2 eyes of 2 patients with $\mathrm{MH}, 1$ eye of a patient with ERM, and 3 eyes of 3 patients with PDR. Moreover, immunostaining with anti-tryptase antibodies was performed in samples obtained from 2 eyes of 2 patients with ERM, 1 eye of a patient with $\mathrm{MH}$, and 3 eyes of 3 patients with PDR. Briefly, the BPM and vitreous core samples were fixed in $4 \%$ paraformaldehyde after collection and rinsed with PBS, followed by blocking treatment with 5\% normal goat serum. The target antibodies were applied in the avidin-biotin-peroxidase complex staining method. Among the 10 BPM and vitreous core samples obtained from those patients, 6 were incubated with anti-chymase antibodies (rabbit polyclonal, 1:500; Abcam Plc., Cambridge, MA, USA) and 4 were incubated with anti-tryptase antibodies (rabbit polyclonal, 1:500; Abcam) at $4^{\circ} \mathrm{C}$ for $48 \mathrm{~h}$. The samples were then rinsed with PBS, and incubated with biotinylated anti-rabbit immunoglobulin $G$ ( 1:1,000; Vector Laboratories) at room temperature for $2 \mathrm{~h}$. Next, the samples were once again rinsed with PBS and incubated with alkaline phosphatase-labeled avidin-biotin complex (Vector Laboratories) at room temperature for $2 \mathrm{~h}$, followed by reaction with ImmPACT TM Vector $^{\circledR}$ Red (Vector Laboratories). The samples were then dried, mounted with Entellan ${ }^{\circledR}$ (Merck KGaA, Darmstadt, Germany), and observed under the BZ-X700 fluorescence microscope.

Immunostaining for Detection of Apoptosis by TUNEL Assay

Terminal deoxynucleotidyl transferase dUTP nick end labeling (TUNEL) staining by using an ApopTag ${ }^{\circledR}$ Peroxidase In Situ Apoptosis Detection kit (MilliporeSigma, Burlington, MA, USA) was performed to detect apoptotic cells in 1 eye of a patient with $\mathrm{MH}$ and 1 eye of a patient with PDR. Color development and nuclear counterstaining were performed using $3,3^{\prime}$-diaminobenzidine tetrahydrochloride-dihydrate and methyl green, respectively.

\section{Results}

\section{Nuclear Staining with Hematoxylin and Mast Cell Staining with Toluidine Blue}

Hematoxylin staining showed numerous nuclei in the BPM of a patient with MH (Fig. 2a), whereas the nuclei were scarcely present in the BPM of a patient with PDR 

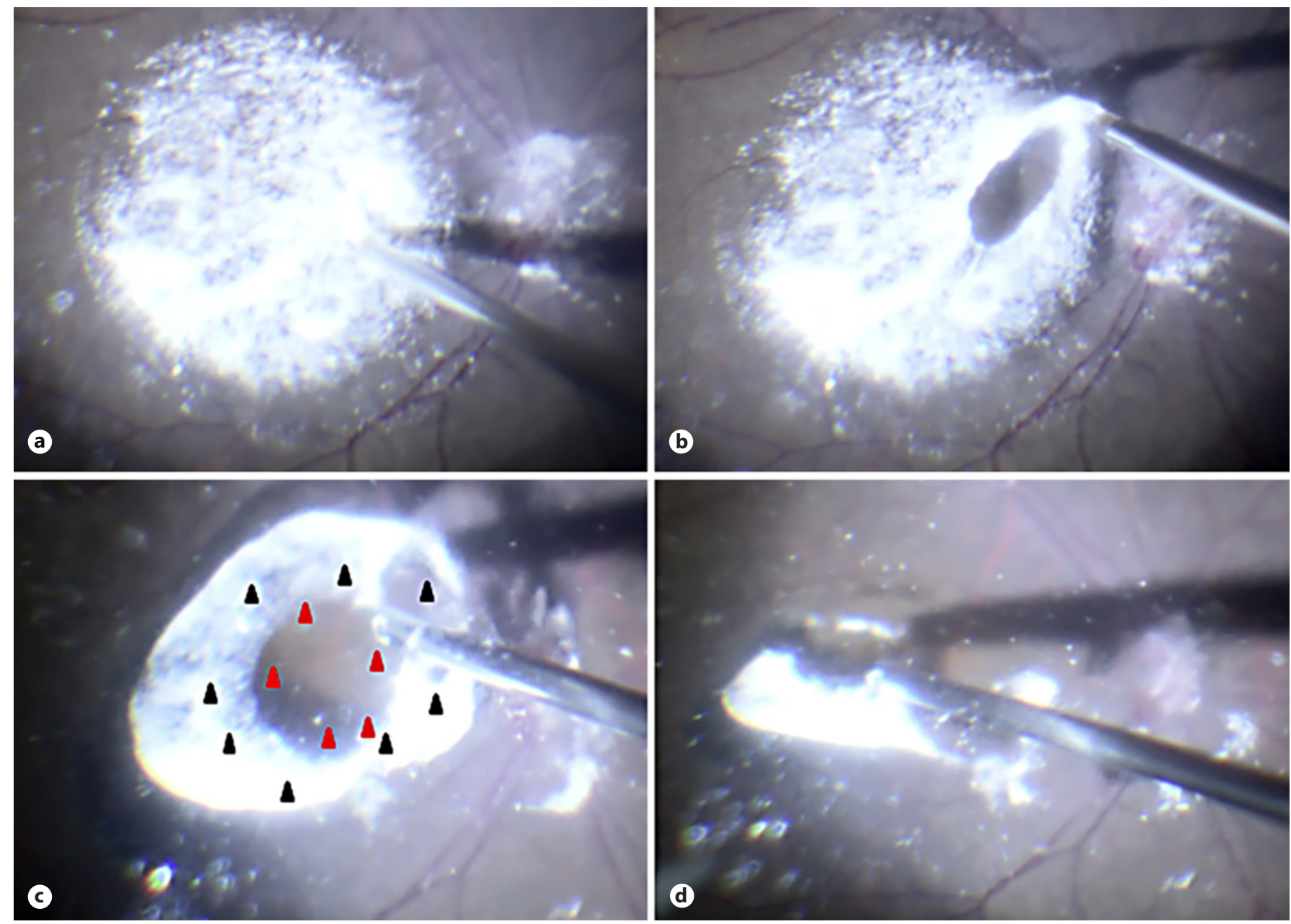

Fig. 1. Images showing the method used for the collection of the BPM samples. a The BPM, an oval-shaped flat vitreous gel, was visualized with an intravitreal injection of TA at the posterior pole of the vitreous. $\mathbf{b}$ Accumulation of TA on the surface of the BPM. A diamond-dusted membrane scraper was then used to make a hole on the anterior wall of the BPM. c After the creation of a hole

(Fig. 2b). Toluidine blue staining showed obvious redpurple metachromasia in the BPM of a patient with $\mathrm{MH}$ (Fig. 3a), whereas the sample obtained from a patient with PDR was poorly stained (Fig. 3b).

\section{Immunostaining with Anti-Chymase and Anti- \\ Tryptase Antibodies}

The vitreous core samples obtained from the 3 patients with $\mathrm{MH}$ or ERM were poorly stained with anti-chymase antibodies, whereas the BPM samples from these patients were particularly well stained (Fig. 4). Chymase staining of both BPM and vitreous core samples was clearly weak-

in the posterior wall (red arrowheads), the BPM was separated from the retinal surface by aspiration of the margin of the hole in the anterior wall (black arrowheads) using a vitreous cutter. $\mathbf{d}$ The floating BPM in the vitreous cavity was then selectively collected with the vitreous cutter. BPM, bursa premacularis; TA, triamcinolone acetonide.

er in patients with PDR than in patients with $\mathrm{MH}$ and ERM (Fig. 5). Similarly, the BPM samples of patients with $\mathrm{MH}$ or ERM were clearly stained with anti-tryptase antibodies (Fig. 6b), while those of the patients with PDR were poorly stained (Fig. 7b).

Immunostaining for Detection of Apoptosis by TUNEL Assay

TUNEL assay revealed that apoptotic cells were more frequently present in the BPM of a patient with $\mathrm{MH}$ than in that of a patient with PDR (Fig. 8b). 


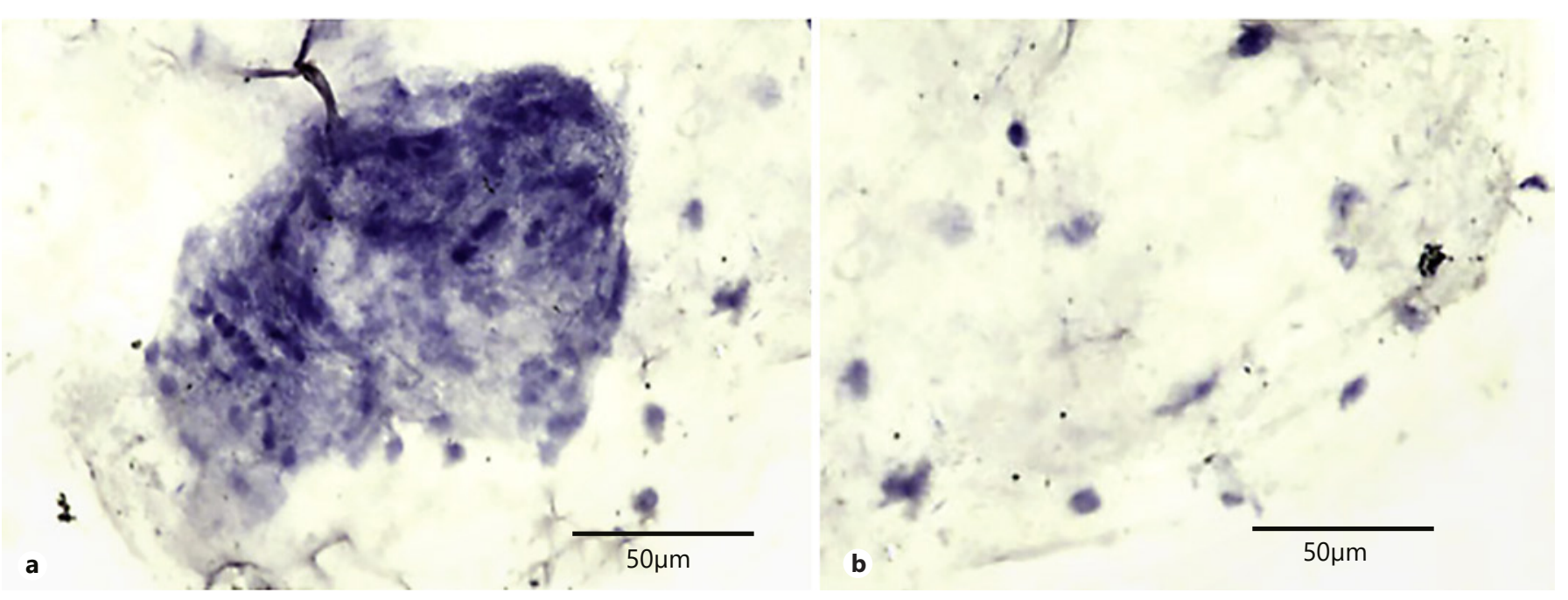

Fig. 2. Images showing nuclear staining of the BPM with hematoxylin. a Hematoxylin staining revealed numerous nuclei in the BPM of a patient with MH. $\mathbf{b}$ Hematoxylin-stained nuclei were scarcely observed in the BPM of a patient with PDR. BPM, bursa premacularis; MH, macular hole; PDR, proliferative diabetic retinopathy.
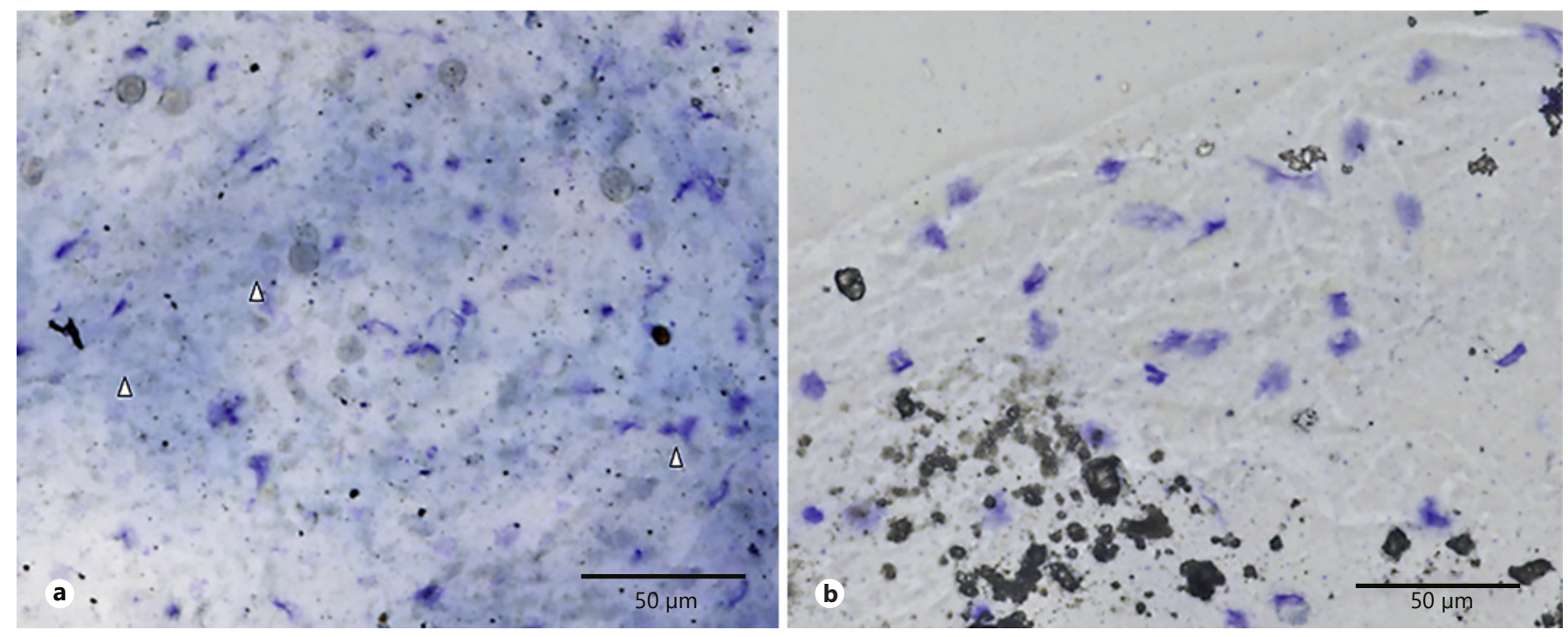

Fig. 3. Images showing mast cell staining of the BPM with toluidine blue. a Toluidine blue staining revealed apparent red-purple (metachromatic staining; white arrowheads) in the BPM of a patient with MH. b The specimens from a patient with PDR were poorly stained with toluidine blue. BPM, bursa premacularis; $\mathrm{MH}$, macular hole; PDR, proliferative diabetic retinopathy.

\section{Discussions}

Mast cells are immune cells of the myeloid lineage and are present in mucosal and connective tissues throughout the body [8]. There are 2 types of mast cells, that is, tryptase-positive mucosal mast cells and tryptase/chymasepositive connective tissue mast cells [9]. Chymase and tryptase, which are mast cell serine proteases, are involved in various physiological and pathological processes, including fibrosis, angiogenesis, and apoptosis, as well as tissue remodeling [10-13].

Mast cells are found in most ocular tissues, such as the choroid, ciliary body, iris, conjunctiva, sclera, and optic nerve [14-16], while the retina is devoid of mast 

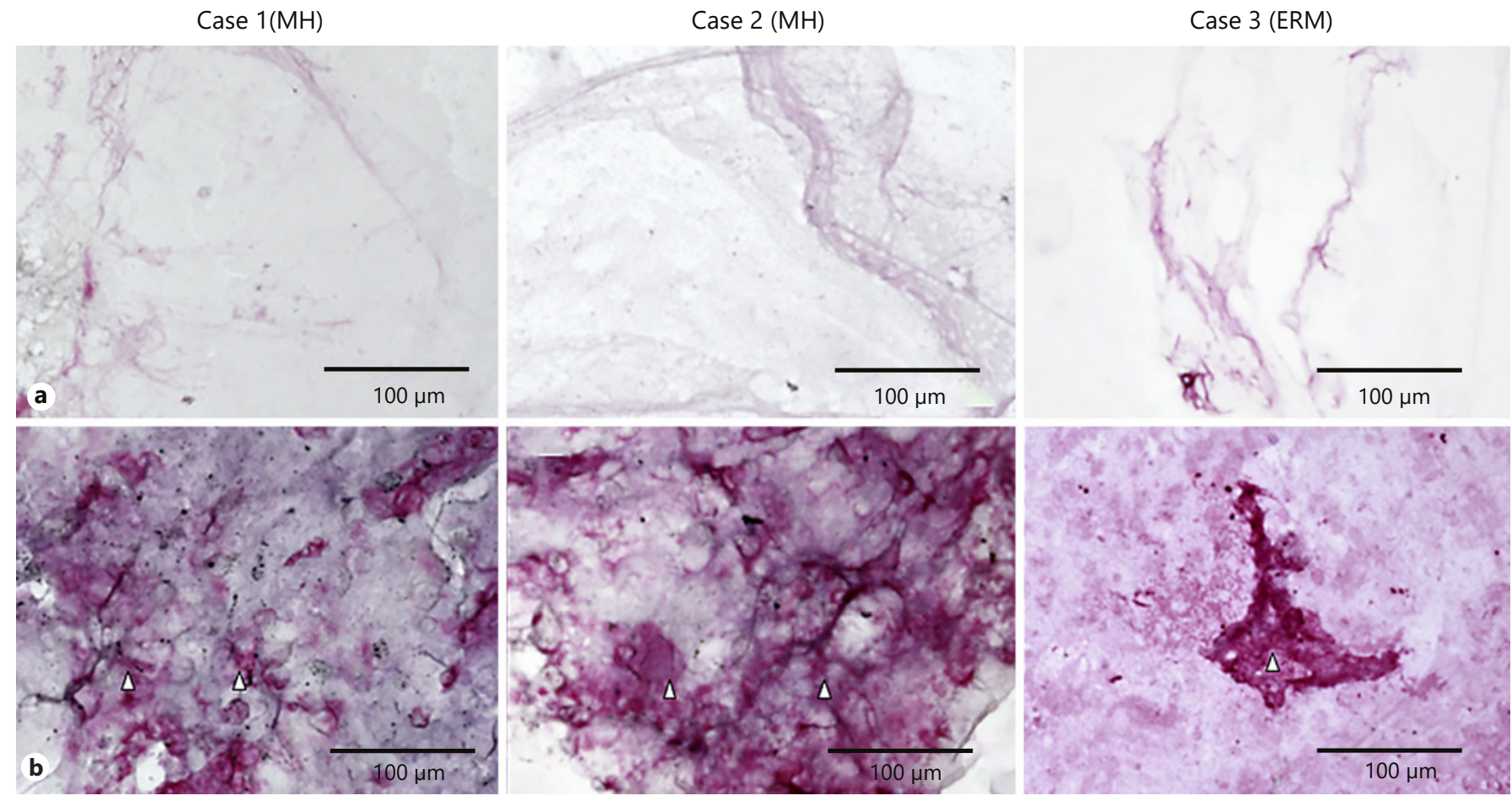

Fig. 4. Images showing immunostaining with anti-chymase antibodies in 3 patients with $\mathrm{MH}$ (case 1 and 2 ) and ERM (case 3). a Chymase staining of the vitreous core samples from MH and ERM patients was weakly positive. $\mathbf{b}$ The BPM samples from MH and ERM patients were intensely stained with anti-chymase antibodies (white arrowheads). BPM, bursa premacularis; $\mathrm{MH}$, macular hole; ERM, epiretinal membrane.

cells [14]. In the vitreous, mast cells reportedly appear only in pathological conditions, such as persistent hyperplastic primary vitreous and Eales' disease $[17,18]$. However, we recently found that mast cells were present in the BPM, which has commonly been considered an empty space, and assumed that they might be the source of chymase and tryptase in the vitreous $[6,7]$. The thin membrane remaining on the macula following core vitrectomy is generally regarded as the posterior wall of the BPM or the posterior vitreous cortex [19]. However, Polak et al. [20] determined that this thin tissue, itself was the whole BPM, based on the observation of the shape of internally migrated TA during vitrectomy. Worst and Los [21], who first reported the discoverer of the BPM, stated that the surface of the BPM had feathery texture $[6,7]$. Thus, we presume that the TA might have accumulated on the anterior wall of the BPM due to the surface features.

The findings in this present study revealed that the BPM samples obtained from the PDR patients contained a very small number of mast cells, compared with those obtained from the MH and ERM patients. These findings appear to be consistent with those of our previous studies, showing that the activities of chymase and tryptase are both decreased in the PDR vitreous $[4,5]$. As has been previously reported, mast cells are involved in angiogenesis and fibrosis in various physiopathological conditions $[10,11]$. Since marked angiogenesis and fibrosis occur in PDR $[22,23]$, the disappearance of pro-angiogenic and pro-fibrotic mast cells from the BPM appears to be rather paradoxical. Lopez et al. [24] reported that mast cells were absent in the diabetic retina and speculated that the mechanism of angiogenesis in PDR might be different from that in tumor-induced angiogenesis, where a high density of mast cells produces angiogenic factors. The vitreous levels of stem cell factor (SCF), interleukin (IL)-6, CCL2/MCP-1, and CXCL12/SDF-1 are increased in PDR [25-28]. These cytokines and chemokines are mast cell chemotactic factors [29-32], and SCF and IL- 6 among them are also differentiation and proliferation factors for mast cells [33-35]. These findings 

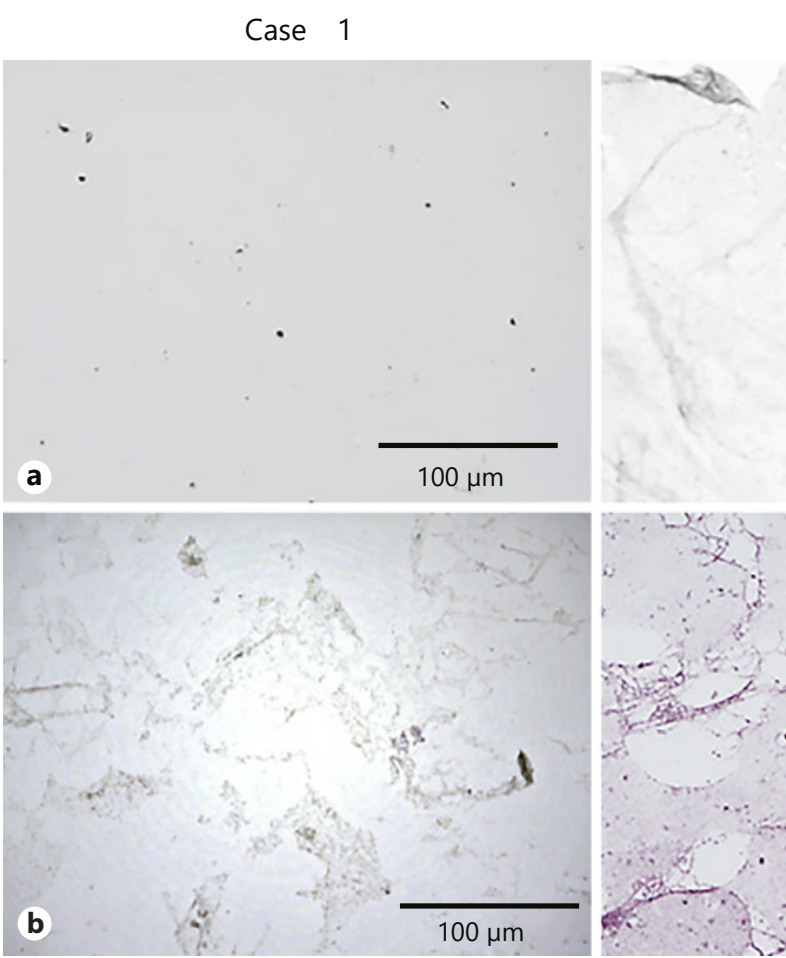

Case

\section{2}
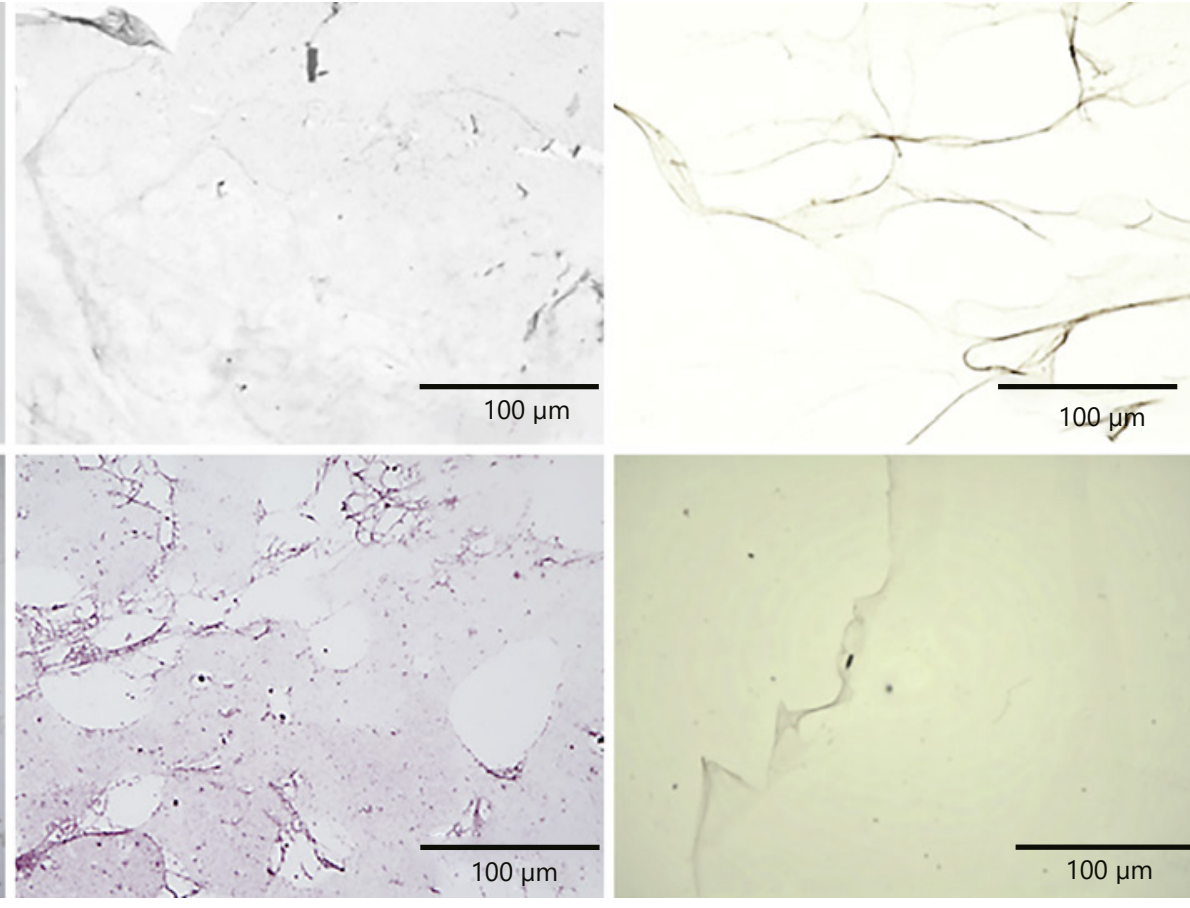

Fig. 5. Images showing immunostaining with anti-chymase antibodies in 3 patients with PDR. a Chymase staining of the vitreous core samples from 3 PDR patients was weakly positive. $\mathbf{b}$ The staining of the BPM samples obtained from PDR patients using anti-chymase antibodies was apparently weaker than those obtained from the $\mathrm{MH}$ and ERM patients (white arrowheads). BPM, bursa premacularis; MH, macular hole; PDR, proliferative diabetic retinopathy; ERM, epiretinal membrane.

seem to be contradictory to our present results that mast cells were scarcely observed in the BPM obtained from PDR patients.

One possibility for the disappearance of mast cells from the BPM in PDR vitreous is that they might be eliminated from the vitreous by apoptosis. Carvalho et al. [36] reported that mast cells were susceptible to apoptosis in alloxan-induced diabetic rats. Moreover, Yoshimaru et al. [37] reported that advanced glycation end products, which reportedly accumulate in the diabetic vitreous $[38,39]$, induced mast cell apoptosis in vitro. However, our TUNEL assay performed in this study indicated that apoptotic cells were more frequently observed in the BPM samples obtained from MH patients than in those obtained from PDR patients (Fig. 8). Therefore, another possibility must be taken into consideration.

Semaphorin 3A (Sema 3A), one of the secreted semaphorins widely distributed in nerve tissues and other organs [40], is known to inhibit mast cell infiltration into tissues [41]. In a study by $\mathrm{Wu}$ et al. [42] the authors' findings revealed that high glucose upregulated Sema $3 \mathrm{~A}$ expression by activating mTOR signaling. Moreover, Joyal et al. [43] reported that Sema 3A was secreted by hypoxic neurons in the avascular retina. Since Sema 3A is reportedly elevated in the vitreous of patients with PDR [44]. Sema3A produced by neurons in hyperglycemic and hypoxic conditions might inhibit mast cell infiltration into the BPM. However, and contrary to this assumption, Zheng et al. [45] reported that the renal density of mast cells increased with progression of diabetic nephropathy, while Aggarwal et al. [46] reported that Sema 3A expression in podocytes was increased in patients with advanced diabetic nephropathy. Thus, we presently consider that the most plausible examination for the lack of mast cells in the BMP of patients with PDR is as follows.

It has generally been believed that the foveola is composed of an inverted cone-shaped zone of specialized Müller cells, that is, the Müller cell cone, which 


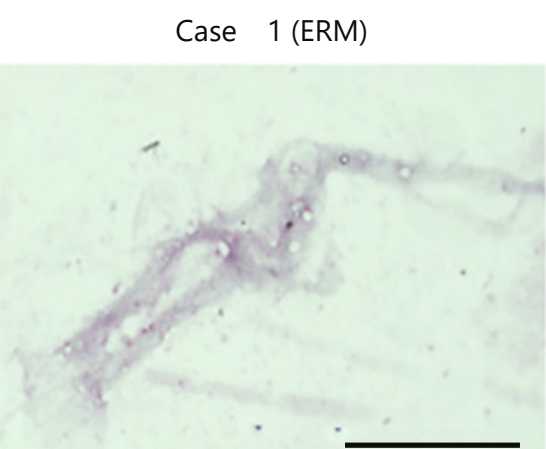

a

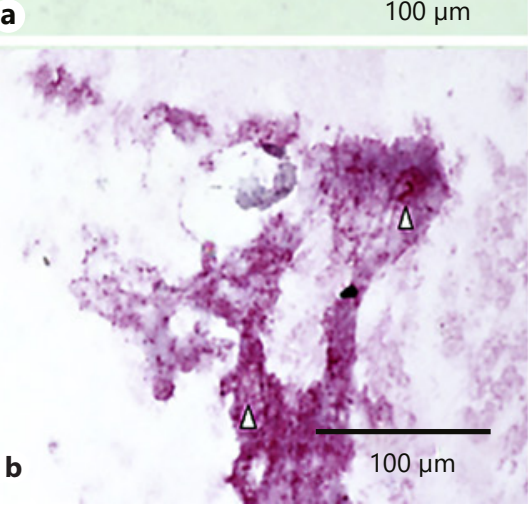

Case 2 (ERM)

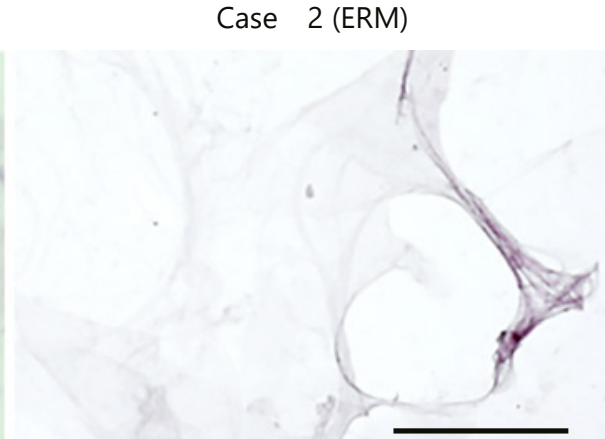

$100 \mu \mathrm{m}$

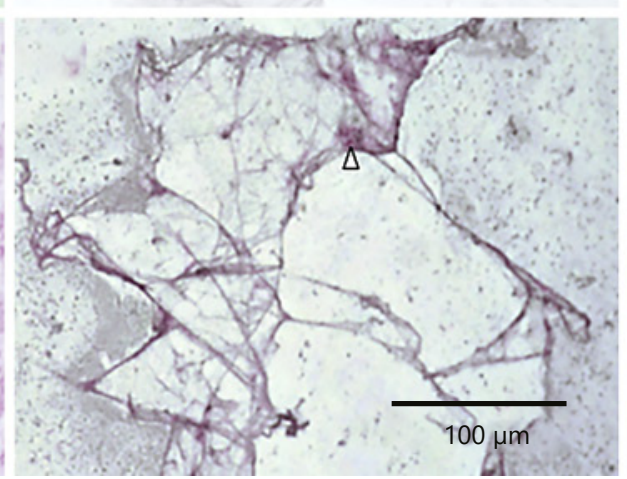

Case

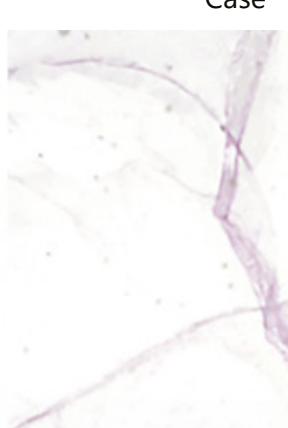

$3(\mathrm{MH})$
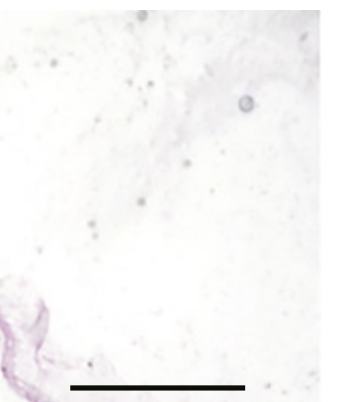

$100 \mu \mathrm{m}$

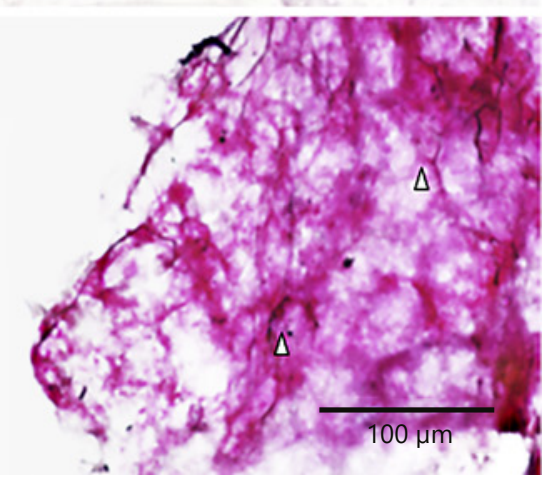

Fig. 6. Images showing immunostaining with anti-tryptase antibodies in 3 patients with ERM (case 1 and 2) and $\mathrm{MH}$ (case 3). a The vitreous core samples obtained from the ERM and MH patients were weakly stained with anti-tryptase antibodies. b The BPM samples obtained from MH and ERM patients were comparatively more stained with anti-tryptase antibodies. BPM, bursa premacularis; MH, macular hole; ERM, epiretinal membrane.

was the hypothesis proposed by Gass [47] in 1999. However, using immunohistological methods, our group [48] and Delaunay et al. [49] showed that the inner-half-portion of the Müller cell cone of the adult primate retina was composed of glial fibrillary acidic protein-positive astrocytes, but not vimentin-positive Müller cells. Kim et al. [50] reported that astrocytes interacted with mast cells through CD40-CD40L, and Seeldrayers et al. [51] indicated that astrocytes supported mast cell viability in vitro, while Xu et al. [52] and El-Hage et al. [53] reported that astrocytes produce mast cell chemotactic factors, such as SCF, IL-6, MCP-1, RANTES, and SDF-1. In a study by Ly et al. [54], the authors reportedly observed early inner retinal astrocyte dysfunction in a streptozotocin-induced diabetic rat model, while Rungger-Brändle et al. [55] reportedly found that the number of astrocytes was significantly reduced in the peripapillary and far peripheral retina in the early phase of diabetes in the rat. Thus, we assume that the dysfunction and decreased number of astrocytes in the surface of the foveola might be related to mast cell disappearance from the BPM in the diabetic patients.

In this present study, we did not observe mast cells in the BPM of the healthy control subjects. However, it is presumed that mast cells may be physiologically present in the BPM due to adult neurogenesis and the generation of new neurons throughout life, which occurs in the subventricular zone and the hippocampus $[56,57]$. Mast cells residing in the hippocampus reportedly store and release serotonin and zinc, which contribute to hippocampal functions, including spatial memory and neurogenesis [58-60]. In our recent study involving an adult monkey model, we reported that retinal stem cells were presumably present in the foveola and its vicinity, where neurogenesis might occur [48]. Thus, we theorize that mast cells in the BPM may constitute a niche around the foveola that maintains the physiological functions and homeostatic regeneration of retinal stem cells. 

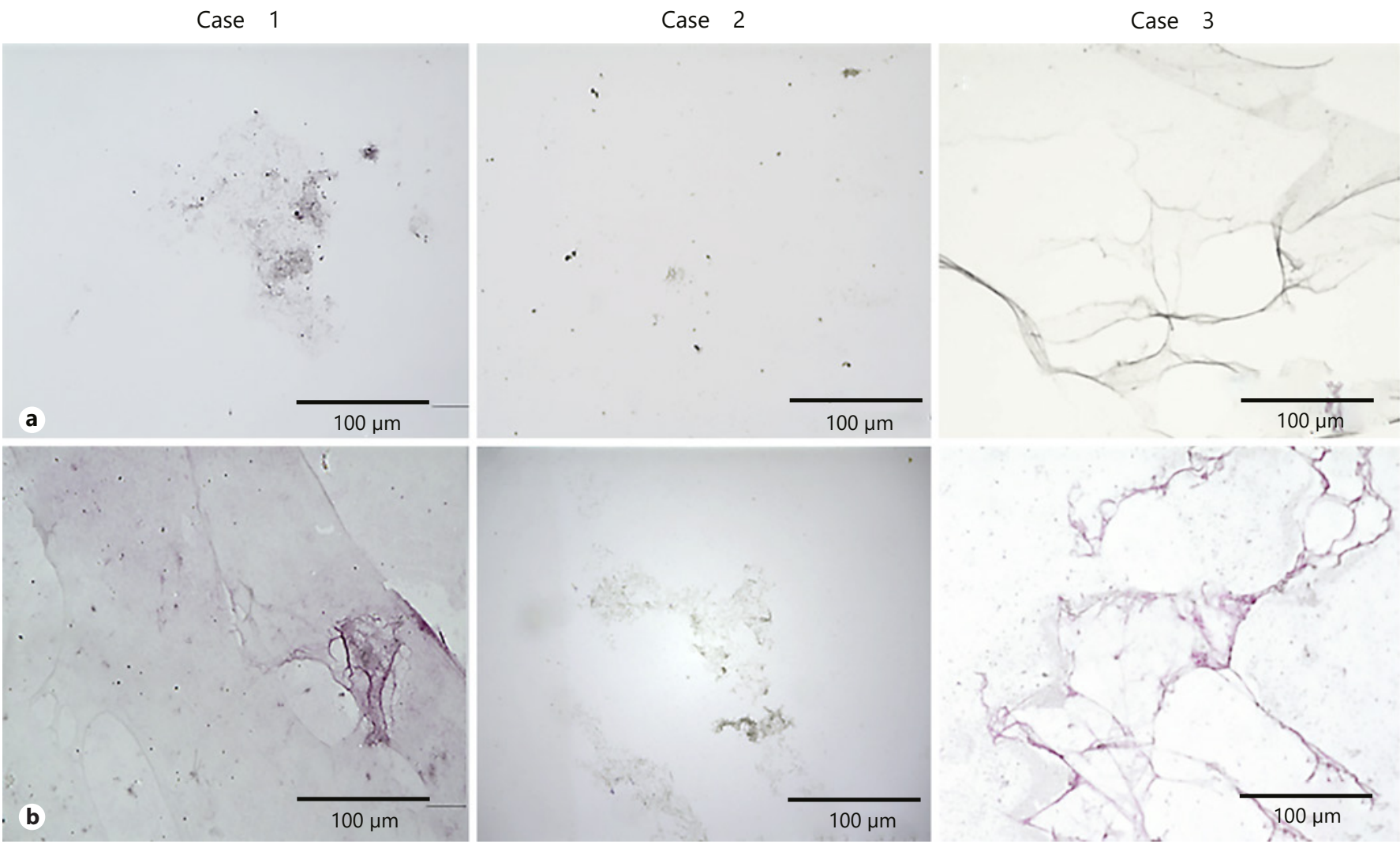

Fig. 7. Images showing immunostaining with anti-tryptase antibodies in 3 PDR patients. a Tryptase staining of the vitreous core samples obtained from PDR patients was weaker than in the samples obtained from $\mathrm{MH}$ and ERM patients. $\mathbf{b}$ The BPM samples obtained from PDR patients were clearly less stained using anti-tryptase antibodies than those obtained from $\mathrm{MH}$ and ERM patients. BPM, bursa premacularis; $\mathrm{MH}$, macular hole; PDR, proliferative diabetic retinopathy; ERM, epiretinal membrane.

Reportedly, diabetic retinopathy and nephropathy are both clinical hallmarks of microangiopathy [61]. Moreover, abnormal angiogenesis and fibrosis are now recognized as features of diabetic nephropathy and retinopathy $[62,63]$. However, contrary to the retina and vitreous of PDR patients, the renal density of mast cells is significantly increased in diabetic patients with nephropathy, as has been previously described $[64,65]$, and chymase expression is increased in the diabetic kidney [66, 67]. Hence, what are the pathological conditions of diabetic retinopathy and nephropathy that might contribute to the discrepancy in the mast cell behavior that is observed between them? In conclusion, elucidation of the cause of the decreased mast cell number in the BPM of PDR patients may provide a clue to a better understanding of the pathogenesis and future treatment options for patients afflicted with PDR.

Mast Cells and Proliferative Diabetic Retinopathy

\section{Acknowledgments}

The authors wish to thank John Bush for reviewing the manuscript.

\section{Statement of Ethics}

This study was approved by the Ethics Committee of Osaka Medical and Pharmaceutical University (approval No. 1134), as was performed in accordance with the tenets set forth in the Declaration of Helsinki. Informed written consent was obtained from all patients for involvement in the study, and for publication of the findings and the accompanying images.

\section{Conflict of Interest Statement}

The authors declare no competing interests.

Ophthalmic Res 2021;64:1002-1012 

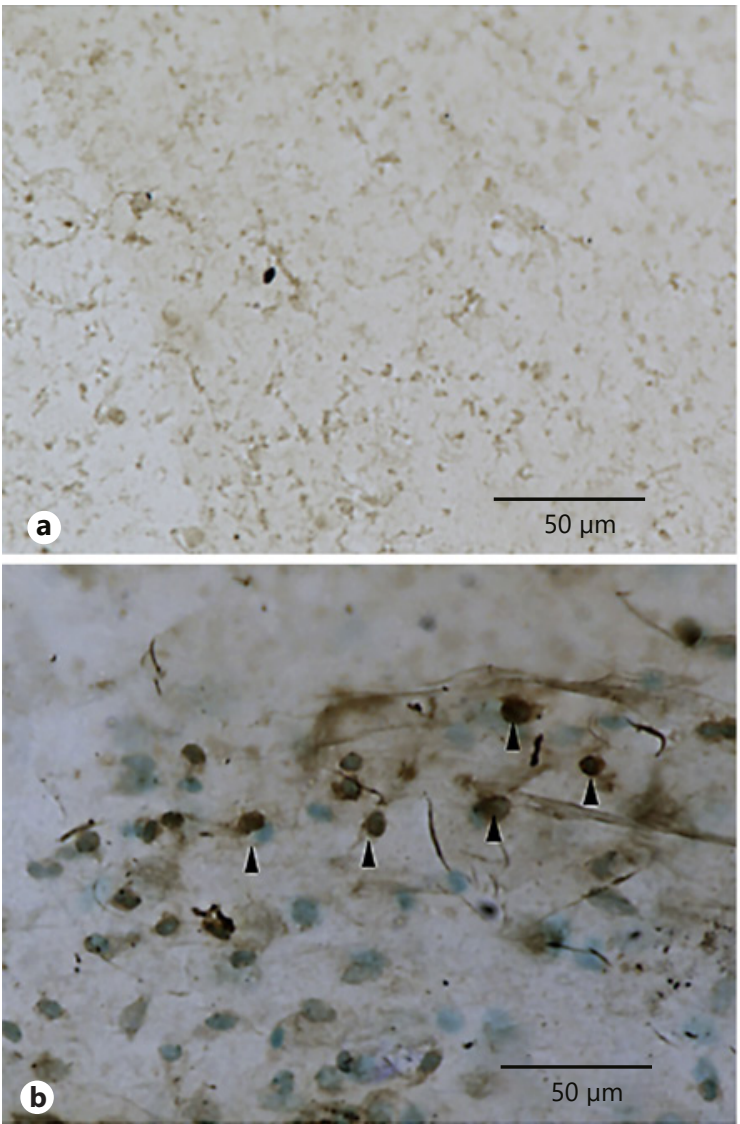

PDR
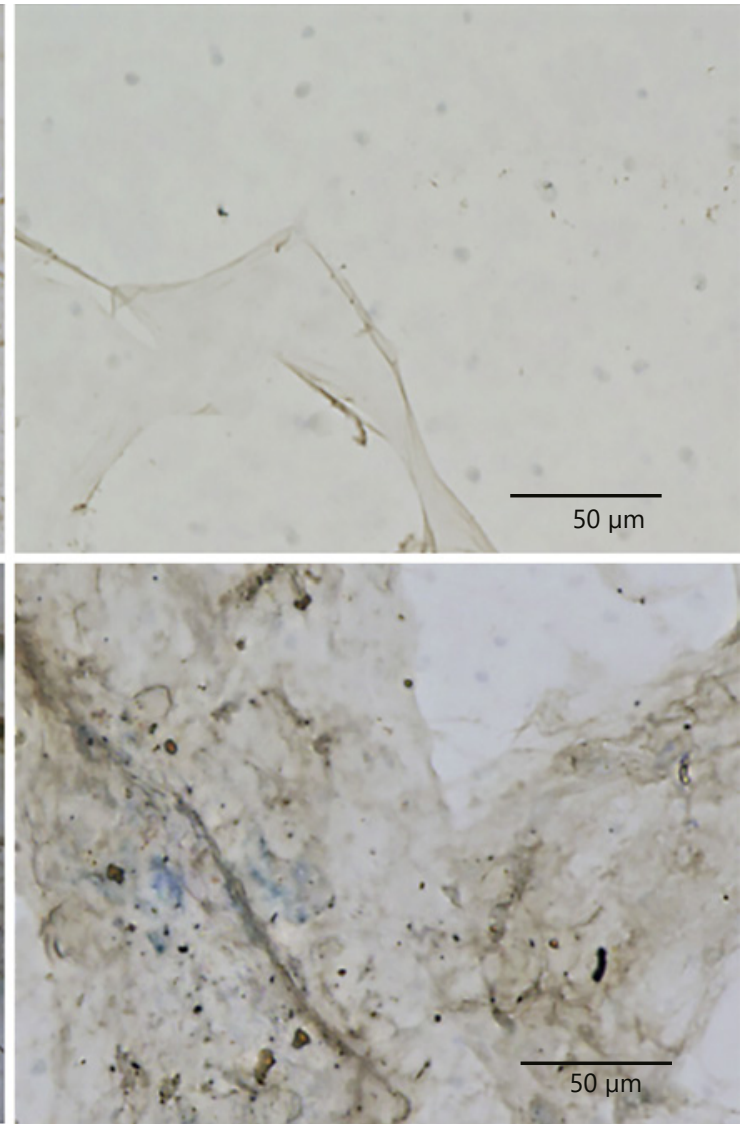

Fig. 8. a, b Images showing immunostaining for the detection of apoptotic cells by TUNEL assay in an eye from $1 \mathrm{MH}$ patient and an eye from 1 PDR patient. ApopTag TUNEL assay revealed that apoptotic cells (black arrowheads) were more frequently present in the BPM obtained from an $\mathrm{MH}$ patient (b, $\mathrm{MH}$; black arrowheads) than that obtained from a PDR patient (b, PDR). BPM, bursa premacularis; MH, macular hole; PDR, proliferative diabetic retinopathy; ERM, epiretinal membrane; TUNEL, terminal deoxynucleotidyl transferase dUTP nick end labeling.

\section{Funding Sources}

Financial support included Grant-in-Aid for Scientific Research (C) (No. 18K09465) from the Japan Society for the Promotion of Science (Tokyo, Japan). The funders had no role in the design or conduct of this research.

\section{Author Contributions}

T.I. conceived and designed the study, obtained data, proposed and performed the statistical analyses, contributed to the literature search, drafted the report, and reviewed/edited the manuscript. K.N., S.M., T.S., and T.H. conceived and designed the study, provided administrative and technical support, con- tributed to the literature search, reviewed/edited the manuscript, and revised the report for important intellectual content. T.K., H.O., S.T., and D.J. reviewed/edited the manuscript and revised the report for important intellectual content. K.N. conceived and designed the study, provided administrative and technical support, contributed to the literature search, reviewed/edited the manuscript, and revised the report for important intellectual content.

\section{Data Availability Statement}

All data generated or analysed during this study are included in this article. Further enquiries can be directed to the corresponding author. 


\section{References}

1 Sandler C, Lindstedt KA, Joutsiniemi S, Lappalainen J, Juutilainen T, Kolah J, et al. Selective activation of mast cells in rheumatoid synovial tissue results in production of TNFalpha, IL-1beta and IL-1Ra. Inflamm Res. 2007 Jun;56(6):230-9.

2 Qin Y, Shi GP. Cysteinyl cathepsins and mast cell proteases in the pathogenesis and therapeutics of cardiovascular diseases. Pharmacol Ther. 2011 Sep;131(3):338-50.

3 Yadav A, Desai RS, Bhuta BA, Singh JS, Mehta R, Nehete AP. Altered immunohistochemical expression of mast cell tryptase and chymase in the pathogenesis of oral submucous fibrosis and malignant transformation of the overlying epithelium. PLoS One. 2014 May 29;9(5):e98719.

4 Maruichi M, Oku H, Takai S, Muramatsu M, Sugiyama T, Imamura Y, et al. Measurement of activities in two different angiotensin II generating systems, chymase and angiotensin-converting enzyme, in the vitreous fluid of vitreoretinal diseases: a possible involvement of chymase in the pathogenesis of macular hole patients. Curr Eye Res. 2004 OctNov;29(4-5):321-5.

5 Ikeda T, Nakamura K, Oku H, Morishita S, Fukumoto M, Suzuki H, et al. The role of tryptase and anti-type II collagen antibodies in the pathogenesis of idiopathic epiretinal membranes. Clin Ophthalmol. 2015 Jun 29;9:1181-6.

6 Sato T, Morishita S, Horie T, Fukumoto M, Kida $\mathrm{T}, \mathrm{Oku} \mathrm{H}$, et al. Involvement of premacular mast cells in the pathogenesis of macular diseases. PLoS One. 2019 Feb 22;14(2):e0211438.

7 Morishita S, Sato T, Oosuka S, Horie T, Kida T, $\mathrm{Oku} \mathrm{H}$, et al. Expression of lymphatic markers in the Berger's space and bursa premacularis. Int J Mol Sci. 2021 Feb 19;22(4):2086.

8 Krystel-Whittemore M, Dileepan KN, Wood JG. Mast cell: a multi-functional master cell. Front Immunol. 2016 Jan 6;6:620.

9 Kambe N, Hiramatsu H, Shimonaka M, Fujino H, Nishikomori R, Heike T, et al. Development of both human connective tissuetype and mucosal-type mast cells in mice from hematopoietic stem cells with identical distribution pattern to human body. Blood. 2004 Feb 1;103(3):860-7.

10 Gruber BL. Mast cells in the pathogenesis of fibrosis. Curr Rheumatol Rep. 2003 Apr;5(2): 147-53.

11 Ribatti D, Crivellato E. Mast cells, angiogenesis, and tumour growth. Biochim Biophys Acta. 2012 Jan;1822(1):2-8.

12 Zhang X, Dong H, Li N, Zhang S, Sun J, Zhang $\mathrm{S}$, et al. Activated brain mast cells contribute to postoperative cognitive dysfunction by evoking microglia activation and neuronal apoptosis. J Neuroinflammation. 2016 May 31;13(1):127.

13 Galli SJ, Tsai M. Mast cells: versatile regulators of inflammation, tissue remodeling, host defense and homeostasis. J Dermatol Sci. 2008 Jan;49(1):7-19.
14 Louden C, Render JA, Carlton WW. Mast cell numbers in normal and glaucomatous canine eyes. Am J Vet Res. 1990 May;51(5): 818-9.

15 Morgan SJ, Williams JH, Walls AF, Church MK, Holgate ST, McGill JI. Mast cell numbers and staining characteristics in the normal and allergic human conjunctiva. J Allergy Clin Immunol. 1991 Jan;87(1 Pt 1):111-6.

16 Levin LA, Albert DM, Johnson D. Mast cells in human optic nerve. Invest Ophthalmol Vis Sci. 1993 Oct;34(11):3147-53.

17 Li L, Lu H, Li B, Li LQ, Gao F. [Histopathological study of retrolental membranes secondary to persistent hyperplastic primary vitreous]. Zhonghua Yan Ke Za Zhi. 2010 Apr; 46(4):317-22. Chinese.

18 Majji AB, Vemuganti GK, Shah VA, Singh S, Das T, Jalali S. A comparative study of epiretinal membranes associated with Eales' disease: a clinicopathologic evaluation. Eye. 2006 Jan;20(1):46-54.

19 Itakura H, Kishi S, Li D, Akiyama H. Observation of posterior precortical vitreous pocket using swept-source optical coherence tomography. Invest Ophthalmol Vis Sci. 2013 May 3;54(5):3102-7.

20 Polak BC, Ringens PJ, Worst JG. Physiological vitreous changes may contribute to the pathogenesis of macular degeneration. Acta Ophthalmol. 2012 Dec;90(8):e652-3.

21 Worst JG, Los LI. Comparative anatomy of the vitreous body in rhesus monkeys and man. Doc Ophthalmol. 1992;82(1-2):16978.

22 El-Asrar AMA, Nawaz MI, Hertogh GD, Alam K, Siddiquei MM, den Eynde KV, et al. S100A4 is upregulated in proliferative diabetic retinopathy and correlates with markers of angiogenesis and fibrogenesis. Mol Vis. 2014 Sep 10;20:1209-24.

$23 \mathrm{Hu}$ YB, Yan H. [Recent advances in the studies of the inhibition of fibrosis in proliferative diabetic retinopathy]. Zhonghua Yan Ke Za Zhi. 2011Apr;47(4):369-72. Chinese.

24 Lopez R, Rand LI, Zetter BR. Absence of mast cells in diabetic retinopathy. Microvasc Res. 1982 Jul;24(1):87-93

25 El-Asrar AMA, Nawaz MI, Kangave D, Siddiquei MM, Geboes K. Angiogenic and vasculogenic factors in the vitreous from patients with proliferative diabetic retinopathy. J Diabetes Res. 2013;2013:539658.

26 Koskela UE, Kuusisto SM, Nissinen AE, Savolainen MJ, Liinamaa MJ. High vitreous concentration of IL- 6 and IL-8, but not of adhesion molecules in relation to plasma concentrations in proliferative diabetic retinopathy. Ophthalmic Res. 2013;49(2): 108-14.

27 Kawashima M, Shoji J, Kamura Y, Sato Y. [Role of chemokines in the vitreous of proliferative diabetic retinopathy]. Nippon Ganka Gakkai Zasshi. 2005 Sep;109(9):596-602. Japanese.
28 Chen LY, Zhuo YH, Li YH, Huang XH, Zhang JL, Li SY, et al. Expression of stromal cell-derived factor-1 in diabetic retinopathy. Chin Med J. 2010 Apr 20;123(8):984-8.

29 Nilsson G, Butterfield JH, Nilsson K, Siegbahn A. Stem cell factor is a chemotactic factor for human mast cells. J Immunol. 1994 Oct 15;153(8):3717-23.

30 Misiak-Tłoczek A, Brzezińska-Błaszczyk E. IL6, but not IL-4, stimulates chemokinesis and TNF stimulates chemotaxis of tissue mast cells: involvement of both mitogen-activated protein kinases and phosphatidylinositol 3-kinase signalling pathways. APMIS. 2009 Aug;117(8): 558-67.

31 Song CH, Joo HM, Han SH, Kim JI, Nam SY, Kim JY. Low-dose ionizing radiation attenuates mast cell migration through suppression of monocyte chemoattractant protein-1 (MCP-1) expression by Nr4a2. Int J Radiat Biol. 2019 Nov;95(11):1498-506.

32 Belot MP, Abdennebi-Najar L, Gaudin F, Lieberherr M, Godot V, Taïeb J, et al. Progesterone reduces the migration of mast cells toward the chemokine stromal cell-derived factor-1/ CXCL12 with an accompanying decrease in CXCR4 receptors. Am J Physiol Endocrinol Metab. 2007 May;292(5):E1410-7.

33 Pompen M, Smids BS, Dingemans KP, Jansen HM, Out TA, Lutter R. Lung epithelial H292 cells induce differentiation of immature human HMC-1 mast cells by interleukin-6 and stem cell factor. Clin Exp Allergy. 2000 Aug; 30(8):1104-12.

34 Bischoff SC, Sellge G, Schwengberg S, Lorentz A, Manns MP. Stem cell factor-dependent survival, proliferation and enhanced releasability of purified mature mast cells isolated from human intestinal tissue. Int Arch Allergy Immunol. 1999 Feb-Apr;118(2-4):104-7.

35 Desai A, Jung MY, Olivera A, Gilfillan AM, Prussin C, Kirshenbaum AS, et al. IL-6 promotes an increase in human mast cell numbers and reactivity through suppression of suppressor of cytokine signaling 3. J Allergy Clin Immunol. 2016 Jun;137(6):1863-71. e6.

36 Carvalho VF, Florim LT, de O Barreto E, Torres RC, Batista MM, Amendoeira FC, et al. Inhibition of advanced glycation end products by aminoguanidine restores mast cell numbers and reactivity in alloxan-diabetic rats. Eur J Pharmacol. 2011 Nov 1;669(1-3): 143-8.

37 Yoshimaru T, Suzuki Y, Inoue T, Nishida S, Ra C. Extracellular superoxide released from mitochondria mediates mast cell death by advanced glycation end products. Biochim Biophys Acta. 2008 Dec;1783(12):2332-43.

38 Stitt AW, Moore JE, Sharkey JA, Murphy G, Simpson DA, Bucala R, et al. Advanced glycation end products in vitreous: structural and functional implications for diabetic vitreopathy. Invest Ophthalmol Vis Sci. 1998 Dec; 39(13):2517-23.
Mast Cells and Proliferative Diabetic Retinopathy
Ophthalmic Res 2021;64:1002-1012 DOI: $10.1159 / 000518438$ 
39 Nakamura N, Hasegawa G, Obayashi H, Yamazaki M, Ogata M, Nakano K, et al. Increased concentration of pentosidine, an advanced glycation end product, and interleukin-6 in the vitreous of patients with proliferative diabetic retinopathy. Diabetes Res Clin Pract. 2003 Aug;61(2):93-101.

40 de Winter F, Kwok JC, Fawcett JW, Vo TT, Carulli D, Verhaagen J. The chemorepulsive protein semaphorin $3 \mathrm{a}$ and perineuronal netmediated plasticity. Neural Plast. 2016;2016: 3679545.

41 Yamaguchi J, Nakamura F, Aihara M, Yamashita N, Usui H, Hida T, et al. Semaphorin $3 \mathrm{~A}$ alleviates skin lesions and scratching behavior in NC/Nga mice, an atopic dermatitis model. J Invest Dermatol. 2008 Dec; 128(12):2842-9.

42 Wu LY, Li M, Qu ML, Li X, Pi LH, Chen Z, et al. High glucose up-regulates semaphorin $3 \mathrm{~A}$ expression via the mTOR signaling pathway in keratinocytes: a potential mechanism and therapeutic target for diabetic small fiber neuropathy. Mol Cell Endocrinol. 2018 Sep 5;472: 107-16.

43 Joyal JS, Sitaras N, Binet F, Rivera JC, Stahl A, Zaniolo $\mathrm{K}$, et al. Ischemic neurons prevent vascular regeneration of neural tissue by secreting semaphorin 3A. Blood. 2011 Jun 2; 117(22):6024-35.

44 Dejda A, Mawambo G, Cerani A, Miloudi K, Shao Z, Daudelin JF, et al. Neuropilin-1 mediates myeloid cell chemoattraction and influences retinal neuroimmune crosstalk. J Clin Invest. 2014 Nov;124(11):4807-22.

45 Zheng JM, Yao GH, Cheng Z, Wang R, Liu $\mathrm{ZH}$. Pathogenic role of mast cells in the development of diabetic nephropathy: a study of patients at different stages of the disease. Diabetologia. 2012 Mar;55(3):801-11.

46 Aggarwal PK, Veron D, Thomas DB, Siegel D, Moeckel G, Kashgarian M, et al. Semaphorin3a promotes advanced diabetic nephropathy. Diabetes. 2015 May;64(5):1743-59.

47 Gass JD. Müller cell cone, an overlooked part of the anatomy of the fovea centralis: hypotheses concerning its role in the pathogenesis of macular hole and foveomacular retinoschisis. Arch Ophthalmol. 1999 Jun; 117(6):821-3.
48 Ikeda T, Nakamura K, Oku H, Horie T, Kida T, Takai S. Immunohistological study of monkey foveal retina. Sci Rep. 2019 Mar 27;9(1):5258.

49 Delaunay K, Khamsy L, Kowalczuk L, Moulin A, Nicolas M, Zografos L, et al. Glial cells of the human fovea. Mol Vis. 2020 Apr 1;26:235-45.

50 Kim DY, Hong GU, Ro JY. Signal pathways in astrocytes activated by cross-talk between of astrocytes and mast cells through CD40CD40L. J Neuroinflammation. 2011 Mar 16; $8: 25$.

51 Seeldrayers PA, Levin LA, Johnson D. Astrocytes support mast cell viability in vitro. J Neuroimmunol. 1992 Feb;36(2-3):239-43.

$52 \mathrm{Xu}$ Q, Wang S, Jiang X, Zhao Y, Gao M, Zhang $\mathrm{Y}$, et al. Hypoxia-induced astrocytes promote the migration of neural progenitor cells via vascular endothelial factor, stem cell factor, stromal-derived factor-1alpha and monocyte chemoattractant protein-1 upregulation in vitro. Clin Exp Pharmacol Physiol. 2007 Jul; 34(7):624-31.

53 El-Hage N, Gurwell JA, Singh IN, Knapp PE, Nath A, Hauser KF. Synergistic increases in intracellular $\mathrm{Ca} 2+$, and the release of MCP-1, RANTES, and IL- 6 by astrocytes treated with Opiates and HIV-1 Tat. Glia. 2005 Apr 15; 50(2):91-106

54 Ly A, Yee P, Vessey KA, Phipps JA, Jobling AI, Fletcher EL. Early inner retinal astrocyte dysfunction during diabetes and development of hypoxia, retinal stress, and neuronal functional loss. Invest Ophthalmol Vis Sci. 2011 Dec 2;52(13):9316-26.

55 Rungger-Brändle E, Dosso AA, Leuenberger PM. Glial reactivity, an early feature of diabetic retinopathy. Invest Ophthalmol Vis Sci. 2000 Jun;41(7):1971-80.

56 Dennis CV, Suh LS, Rodriguez ML, Kril JJ, Sutherland GT. Human adult neurogenesis across the ages: an immunohistochemical study. Neuropathol Appl Neurobiol. 2016 Dec;42(7):621-38.

57 Kim C, Pinto AM, Bordoli C, Buckner LP, Kaplan PC, Del Arenal IM, et al. Energy restriction enhances adult hippocampal neurogenesis-associated memory after four weeks in an adult human population with central obesity; a randomized controlled trial. Nutrients. 2020 Feb 28;12(3):638
58 Flores JA, Ramírez-Ponce MP, Montes MÁ, Balseiro-Gómez S, Acosta J, Álvarez de Toledo G, et al. Proteoglycans involved in bidirectional communication between mast cells and hippocampal neurons. J Neuroinflammation. 2019 May 20;16(1):107.

59 Nautiyal KM, Dailey CA, Jahn JL, Rodriquez E, Son NH, Sweedler JV, et al. Serotonin of mast cell origin contributes to hippocampal function. Eur J Neurosci. 2012 Aug;36(3): 2347-59.

60 Kennedy RH, Wiqas A, Curley JP. Evidence for mast cell-mediated zinc homeostasis: increased labile zinc in the hippocampus of mast-cell deficient mice. Neurosci Lett. 2017 May 22;650:139-45.

61 Parving HH. Diabetic hypertensive patients. Is this a group in need of particular care and attention? Diabetes Care. 1999 Mar;22(Suppl 2):B76-9.

62 Nakagawa T, Sato W, Kosugi T, Johnson RJ. Uncoupling of VEGF with endothelial NO as a potential mechanism for abnormal angiogenesis in the diabetic nephropathy. J Diabetes Res. 2013;2013:184539.

63 Zeng LF, Xiao Y, Sun L. A glimpse of the mechanisms related to renal fibrosis in diabetic nephropathy. Adv Exp Med Biol. 2019; 1165:49-79.

64 Okoń K, Stachura J. Increased mast cell density in renal interstitium is correlated with relative interstitial volume, serum creatinine and urea especially in diabetic nephropathy but also in primary glomerulonephritis. Pol J Pathol. 2007;58(3):193-7.

65 Zheng JM, Yao GH, Cheng Z, Wang R, Liu $\mathrm{ZH}$. Pathogenic role of mast cells in the development of diabetic nephropathy: a study of patients at different stages of the disease. Diabetologia. 2012 Mar;55(3):801-11.

66 Huang XR, Chen WY, Truong LD, Lan HY. Chymase is upregulated in diabetic nephropathy: implications for an alternative pathway of angiotensin II-mediated diabetic renal and vascular disease. J Am Soc Nephrol. 2003 Jul; 14(7):1738-47.

67 Cristovam PC, Carmona AK, Arnoni CP, Maquigussa E, Pereira LG, Boim MA. Role of chymase in diabetic nephropathy. Exp Biol Med. 2012 Aug;237(8):985-92. 